\title{
Synthesis of derivatives of $\beta$-sitosterol and evaluation of their anti-bacterial activity
}

\section{L.A.M. Fernando, W.G.D. Wickramasingha and S. Jayasinghe*}
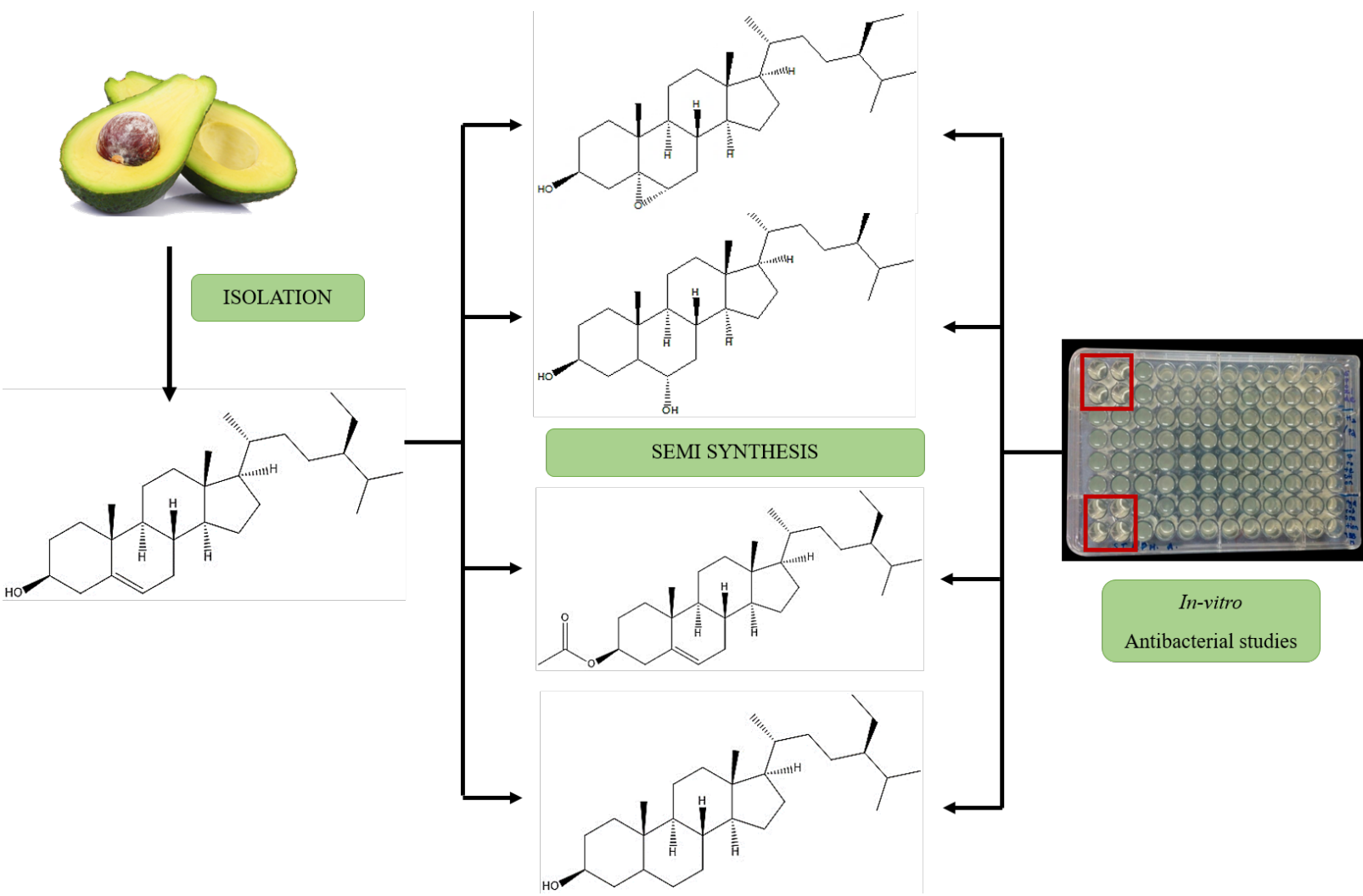

\section{Highlights}

- $\beta$-Sitosterol was isolated from ripen fruits of Avocado with a relatively good yield.

- Four derivatives were synthesized and C6 hydroxy $\beta$-sitosterol was reported for the first time.

- The anti-bacterial activity was reduced for derivatives with increasing lipophilicity.

- Hydroxyl groups at C3 and C6 are significant towards the antibacterial activity. 


\title{
RESEARCH ARTICLE
}

\section{Synthesis of derivatives of $\boldsymbol{\beta}$-sitosterol and evaluation of their anti-bacterial activity}

\author{
L.A.M. Fernando ${ }^{1}$, W.G.D. Wickramasingha ${ }^{2}$ and S. Jayasinghe ${ }^{1, *}$ \\ ${ }^{1}$ Department of Chemistry, Faculty of Science, University of Peradeniya, Peradeniya, Sri Lanka. \\ ${ }^{2}$ Department of Biochemistry, Medical Research Institute, Colombo, Sri Lanka.
}

Received: 26/05/2021 ; Accepted: 29/09/2021

\begin{abstract}
Antimicrobial resistance is one of a major health issue and warrants the development of new antimicrobial agents with structural diversity and novel mechanisms of action. $\beta$-Sitosterol is naturally abundant steroid in many plant families that shows moderate antibacterial activity. Hence, this study aimed to identify the importance of the functional groups present in $\beta$-sitosterol in enhancing the antibacterial activity. $\beta$-Sitosterol was isolated from the dichloromethane extract of fruit pulps of Persea americana (Yield 2.3\% with respect to the crude). Isolated $\beta$-sitosterol was subjected to epoxidation, hydrogenation, and anti-Markovnikov hydration at the endocyclic olefin at $\mathrm{C} 5-\mathrm{C} 6$, and the acetylation at C3- hydroxyl group. The parent compound and semisynthetic derivatives were characterized using ${ }^{1} \mathrm{H}-\mathrm{NMR}$ and FTIR and their antibacterial activity was determined using the micro broth dilution method with respect to the oxacillin and amoxicillin. The derivative with C6 hydroxyl of $\beta$-sitosterol was reported for the first time. The minimum inhibition concentrations of $\beta$-sitosterol, epoxide, and C6 hydroxyl compound were $512 \mathrm{ppm}$, and that of hydrogenated and acetylated compounds were above $1024 \mathrm{ppm}$. These empirical data revealed that the incorporation of oxygen heteroatom at the $\mathrm{C} 5$ and $\mathrm{C} 6$ positions while removing the double bond character at $\mathrm{C} 5-\mathrm{C} 6$ has not affected the antibacterial activity of $\beta$-sitosterol, however, hydrogenation and acetylation at the C3 hydroxyl group have significantly reduced the antibacterial activity compared to the $\beta$-sitosterol.
\end{abstract}

Keywords: $\beta$-sitosterol; epoxidation; anti-Markovnikov hydration; hydrogenation; acetylation; antibacterial activity.

\section{INTRODUCTION}

Bacterial infections are one of the major global health problems due to the growing resistance of bacteria to the available antibiotics as a result of misuse and overuse of them. Especially it is a heavy burden for developing and lowincome countries as many patients with resistant bacterial infections are difficult to be cured and hence increasing the morbidity and mortality while causing a further escalation of the cost of health care delivery (Bygbjerg, 2011; Coker et al., 2011). Hence exploring the avenues for new antibiotics is always at utmost importance to overcome the issues related to resistant bacterial infections.

Natural products and their derivatives play a huge role in exploring new antibiotics owing to their vast structural diversity, metabolic stability, and ability of being used as safe and broadly effective alternatives with less adverse effects (Sasidharan et al., 2011). Many new antibiotics have been developed through the chemical modification of natural compounds such as $\beta$-lactams, carbapenems, and cephalosporin. Approximately, one-third of the top-selling drugs in the world are natural products or their derivatives (Newmann and Gordon, 2016). But with the identification of antibiotic-resistant bacterial strains towards the available standard antibiotics scientists put their focus on synthesizing derivatives of natural products which are already being used as antibiotics. A better example for this is the very first glycopeptide antibiotic; vancomycin which was the most commonly used drug in the treatment of Gram-positive bacterial infections that were resistant to common antibiotics, some decades ago. As vancomycin-resistant bacterial strains emerged, derivatives of vancomycin had been synthesized and tested for the antibacterial activity for vancomycin-resistant strains. Nagarajan et al. (1993) and Ge et al. (1999) have reported that carbohydrate derivatives of vancomycin are more active against vancomycin-resistant bacterial strains and hence serve as a great solution for antibiotics resistance. Consequently with these findings and subsequent efforts of the number of other scientists, a semi-synthetic derivative of vancomycin; telavancin was approved in 2007 for methicillin-resistant bacterial strains (Food and Drug Administration, United States). However, the development and introduction of new antibiotics and observation of resistant organisms would be a never-ending process.

Synthesis of derivatives of common natural antibacterial compounds would not only explain the structureactivity relationships of their inherent properties but also suggests the potential alternatives that could be effective in the treatment of these resistant bacterial infections. The present study was carried out as a preliminary step towards finding potent antibiotic drug leads using $\beta$-sitosterol which is abundant in many plant families.

$\beta$-Sitosterol (compound 1) is a steroid that has a chemical structure similar to cholesterol (Figure 1) and has been easily isolated from fruits such as avocado, vegetable oils, and nuts such as soybeans. It is reported to have diverse bio-activities such as anti-inflammatory activity, 
hypocholesterolaemic activity, anti-cancer activity, and angiogenic activity (Saeidnia et al., 2014). Although many scientists claim that $\beta$-sitosterol has potential antibacterial activity (Sanches et al., 2005; Sen et al., 2012), some of them has proven that antibacterial activity of $\beta$-sitosterol is less when compared with standard antibiotics (Chandramu et al., 2003; Li et al., 2008; Kongkathip et al., 2009). Even though there are controversial statements on its antibacterial activity, its natural abundance and inherited various biological activities made our interest to produce semisynthetic derivatives of $\beta$-sitosterol in order to enhance the antibacterial activity and to study the structure-activity relationship. Four different derivatives of $\beta$-sitosterol were synthesized by either modifying the double bond at the C5-C6 by epoxidation (2), hydrogenation (3), and antiMarkovnikov hydration (5), or the hydroxyl group at C3 by acetylation (4) in our study. Antibacterial activities of $\beta$-sitosterol and its semisynthetic derivatives (compounds $1-5)$ were evaluated using the micro broth dilution method as per the procedure given by the Clinical and Laboratory Standards Institute (CLSI, 2018).

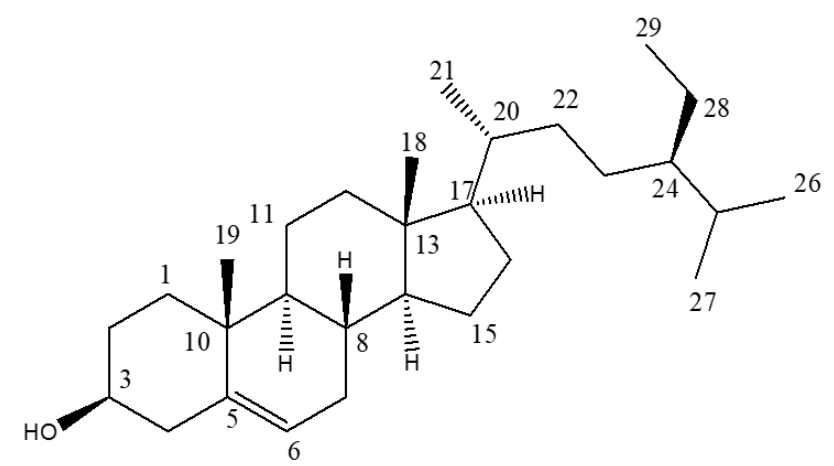

Figure 1: Chemical structure of Compound 1.

\section{MATERIALS AND METHODS}

General ${ }^{1} \mathrm{H}-\mathrm{NMR}$ spectra were performed on a Varian Mercury $300 \mathrm{MHz}$ using $\mathrm{CDCl}_{3}$ as the solvent and infrared spectra were recorded on an FTIR Perkin Elmer spectrophotometer. Flash Column Chromatography (FCC) refers to chromatography carried out through columns packed with Euclid silica gel 60 (0.040-0.063 mm). Fractions from FCC subjected to Thin Layer Chromatography (TLC) with $0.1 \mathrm{~mm}$ thick 60F $254 \mathrm{Kiesel} \mathrm{G.} \mathrm{MERCK} \mathrm{plates} \mathrm{with}$ art 230 - 400 ASTM silica gel as stationary phase and with dichloromethane (DCM)/hexane (6/4) as eluent and visualized with anisaldehyde-sulphuric acid followed by heating.

\section{Preparation of plant extract}

Persea americana fruits were purchased from the market in Kandy, Sri Lanka. Fruit pulp was freeze-dried in order to remove water and a $50 \mathrm{~g}$ sample was macerated for $3 \times 24 \mathrm{~h}$ in DCM $(300 \mathrm{~mL})$ with constant shaking. A well-refined solution was filtered and concentrated under reduced pressure at $30^{\circ} \mathrm{C}$.
Isolation of $(3 \mathrm{~S}, 8 \mathrm{~S}, 9 \mathrm{~S}, 10 \mathrm{R}, 13 \mathrm{R}, 14 \mathrm{~S}, 17 \mathrm{R})-17-[(2 \mathrm{R}, 5 \mathrm{R})-$ 5-ethyl-6-methylheptan-2-yl]-10,13-dimethyl-

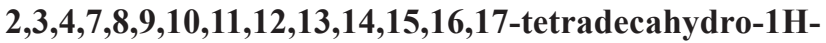
cyclopenta[a]phenanthren-3-ol (Compound 1)

The DCM extract (6.187 g) was fractionated using FCC with gradient solvent systems of hexane and DCM. The fractions were subjected to TLC and those that contained the targeted compound whose $R_{f}$ value $(0.58$, 60\% DCM: hexane) was matched with the authentic sample were combined together and again subjected to FCC under isocratic elution with 60\% DCM: hexane. The test tubes which contain pure compound were combined and characterized for structure elucidation.

The isolated compound was obtained as white needle like crystals. Comprehensive analysis of FTIR and ${ }^{1} \mathrm{H}-\mathrm{NMR}$ (Praveen et al., 2011) of the isolated compound confirmed that it is $\beta$-sitosterol. FTIR ( $\left.v \operatorname{max~cm} \mathrm{cm}^{-1}\right): 3437(-\mathrm{OH}), 2877$ and 2954 (aliphatic $-\mathrm{CH}), 1654(-\mathrm{C}=\mathrm{C}), 1052 \quad(-\mathrm{C}-\mathrm{O})$. ${ }^{1} \mathrm{H}-\mathrm{NMR}(\delta \mathrm{ppm}): 0.62-0.84(\mathrm{~m}, 13 \mathrm{H}), 0.88$ (s, 3H), 0.931.00 (d, $J=6.8 \mathrm{~Hz}, 3 \mathrm{H}), 1.03-1.31(\mathrm{~m}, 5 \mathrm{H}), 1.34-2.09$ (m, 19H), 2.15 (m, 1H), 2.22 (dd, $J=14.5,2.3 \mathrm{~Hz}, 1 \mathrm{H}), 2.26$ (dd, $J=14.5,2.3 \mathrm{~Hz}, 1 \mathrm{H}), 3.51(\mathrm{H} 3, \mathrm{~m}, 1 \mathrm{H}), 5.33$ (H6, m, $1 \mathrm{H})$.

Synthesis of ([3S,4aS,5aR,6aS,6bS,9R,9aR,11aS,11bR]9-[(2R,5R)-5-ethyl-6-methylheptan-2-yl]-9a,11b-dimet hylhexadecahydrocyclopenta $[1,2]$ phenanthro $[8 a, 9-b]$ oxiren-3-ol) (Compound 2)

Compound 2 was synthesized according to the modified procedure described by Rega et al. (2007). To a solution of compound 1 (30 mg, $0.0723 \mathrm{mmol})$ in DCM $(0.511 \mathrm{~mL})$ at $0{ }^{\circ} \mathrm{C}$ was added $m$-chloroperbenzoic acid ( $m$-CPBA) (32.439 $\mathrm{mg}, 0.1879 \mathrm{mmol})$ in DCM $(0.511 \mathrm{~mL})$ dropwise under $\mathrm{N}_{2}$ atmosphere. The mixture was allowed to warm to room temperature and stirred for $20 \mathrm{~h}$, then it was cooled to $0{ }^{\circ} \mathrm{C}$ and $\mathrm{Na}_{2} \mathrm{SO}_{3}(10 \%, 2.55 \mathrm{~mL})$ was added, and the mixture was kept at this temperature for $6 \mathrm{~h}$. Then the aqueous phase was extracted with DCM $(2 \mathrm{~mL} \times 3)$. The combined organic extracts were washed with water (4 mL), dried with $\mathrm{Na}_{2} \mathrm{SO}_{4}$, and concentrated under reduced pressure. The residue was flash chromatographed using $70 \%$ DCM in hexane to give compound 2 as a single isomer (27.9 mg, 93\%).

Compound 2 was obtained as white needle like crystals. FTIR ( $v$ max cm$\left.{ }^{-1}\right): 3444(\mathrm{OH}), 2814$, and 2931 (aliphatic -CH), 1018 (-C-O). ${ }^{1} \mathrm{H}-\mathrm{NMR}$ ( $\left.\delta \mathrm{ppm}\right):$ 1.29-0.64 (m, $\left.25 \mathrm{H}\right)$, 1.95 (m, 7H), 2.08 (H7, m, 2H), 2.91 (H6, dd, $J=6.6,1.3$ $\mathrm{Hz}, 1 \mathrm{H}), 3.93$ (H3, m, 1H).

\section{Synthesis of $\quad[(3 S, 8 R, 9 S, 10 S, 13 R, 14 S, 17 R)-17-$ [(2R,5R)-5-ethyl-6-methylheptan-2-yl]-10,13- dimethylhexadecahydro-1 H-cyclopent a [ a ] phenanthren-3-ol] (Compound 3)}

Compound 3 was synthesized according to the modified procedure described by Augustine and Reardon, (1969). A mixture of compound 1 (30 mg, $0.0723 \mathrm{mmol})$ in anhydrous methanol $(2.79 \mathrm{~mL})$ was hydrogenated over palladium on 
charcoal (1.5 mg, 5\%) at room temperature. After $10 \mathrm{~h}$, the catalyst was removed by filtration and the solvent was evaporated under reduced pressure and the residue was passed through a column using 60\% DCM: hexane to give compound 3 (29.1 mg, 96\%).

Compound 3 was a white crystalline compound. FTIR $\left(v \max \mathrm{cm}^{-1}\right): 3464(-\mathrm{OH}), 2765$ and 2985 (aliphatic-CH), $1014(-\mathrm{C}-\mathrm{O}) .{ }^{1} \mathrm{H}-\mathrm{NMR}(\delta \mathrm{ppm})$ : $0.87-1.20$ $(\mathrm{m}, 18 \mathrm{H}) 1.27(\mathrm{~s}, 6 \mathrm{H}) 1.39(\mathrm{~s}, 13 \mathrm{H}) 1.77(\mathrm{~s}, 10 \mathrm{H}) 2.07$ (s, $1 \mathrm{H}) 3.77$ (H3, m, $1 \mathrm{H})$.

Synthesis of $[(3 S, 8 S, 9 S, 10 R, 13 R, 14 S, 17 R)-17-[(2 R$, 5R)-5-ethyl-6-methylheptan-2-yl]-10,13-dimethyl$2,3,4,7,8,9,10,11,12,13,14,15,16,17$-tetradecahydro-1Hcyclopenta[a]phenanthren-3-yl acetate] (Compound 4)

Compound 4 was synthesized according to the modified procedure described by Rali et al. (2016). To a mixture of compound 1 (30 mg, $0.0723 \mathrm{mmol}$.) in pyridine ( $1 \mathrm{~mL})$ was added acetic anhydride $(1.5 \mathrm{~mL})$ in a $50 \mathrm{~mL}$ round bottom flask. The mixture was stirred for $12 \mathrm{~h}$ at room temperature. The product was poured into $5 \mathrm{~mL}$ of water and stirred for $2 \mathrm{~h}$ to hydrolyze excess acetic anhydride. Then the aqueous phase was extracted with DCM $(2 \mathrm{~mL} \times 3)$. The combined organic extracts were washed with water $(4 \mathrm{~mL})$, dried with anhydrous $\mathrm{Na}_{2} \mathrm{SO}_{4}$, filtered, and concentrated under reduced pressure. The residue was subjected to FCC using 60\% DCM: hexane to give compound 4 (29 mg, 96\%).

Compound 4 was a white needle like crystalline compound. FTIR ( $v$ max cm $\left.{ }^{-1}\right): 2927$ (aliphatic $\left.-\mathrm{CH}\right), 1751$ $(-\mathrm{C}=\mathrm{O}), 1654(-\mathrm{C}=\mathrm{C}), 1276(-\mathrm{C}-\mathrm{O}) .{ }^{1} \mathrm{H}-\mathrm{NMR}(\delta \mathrm{ppm}): 0.86$ $(\mathrm{s}, 9 \mathrm{H}), 1.28(\mathrm{~m}, 31 \mathrm{H}), 1.86(\mathrm{~s}, 4 \mathrm{H}), 2.05(\mathrm{~s}, 5 \mathrm{H}), 2.33$ (H7, m, 2 H), 4.62 (H3, m, 1H), 5.39 (H6, s, 1H).

Synthesis of $\quad[(3 S, 8 S, 9 S, 10 R, 13 R, 14 S, 17 R)-17-$ [(2R,5R)-5-ethyl-6-methylheptan-2-yl]-10,13dimethylhexadecahydro-1 H-cyclopenta [a] phenanthrene-3,6-diol] (Compound 5).

Compound 5 was synthesized according to the modified procedure described by Bracher and Litz, 1996. To a mixture of compound 1 (30 mg, $0.0723 \mathrm{mmol})$ in THF (1 mL) at $0{ }^{\circ} \mathrm{C}$ was added 9-borabicyclo (3.3.1) nonane (9-BBN) (434 $\mu \mathrm{L}, 0.2169 \mathrm{mmol})$ dropwise with stirring over a period of $5 \mathrm{~min}$. The reaction mixture was stirred at room temperature for $45 \mathrm{~min}$. Then $\mathrm{NaOH}$ and $\mathrm{H}_{2} \mathrm{O}_{2}(7.45 \mu \mathrm{L})$ were added, stirred for a few minutes, and extracted with ethyl acetate $(2 \mathrm{~mL} \times 3)$. The combined organic extracts were washed with $1 \% \mathrm{HCl}$ to remove any $\mathrm{NaOH}$ and then with water to remove any trace of acid, dried with $\mathrm{Na}_{2} \mathrm{SO}_{4}$, filtered, and concentrated under reduced pressure. The residue was purified by FCC using solvent combinations of DCM, hexane, and ethyl acetate to give compound 5 (21 mg, 70\%).

Compound 5 was a light yellow needle like crystalline compound. FTIR ( $\left.v \max \mathrm{cm}^{-1}\right): 3444(-\mathrm{OH})$, 2970 (aliphatic -CH), 1060 (-C-O). ${ }^{1} \mathrm{H}-\mathrm{NMR}$ ( $\left.\delta \mathrm{ppm}\right)$ : 1.03 (s, $4 \mathrm{H}), 1.07-1.23$ (m, $6 \mathrm{H}), 1.28$ (s, $4 \mathrm{H}), 1.32-1.52$ $(\mathrm{m}, 12 \mathrm{H}), 1.62-1.78(\mathrm{~m}, 16 \mathrm{H}), 1.90(\mathrm{~m}, 2 \mathrm{H}), 2.08-2.41$ (m, $1 \mathrm{H}), 3.82-3.85$ (H3, H6, m, 2 H).

\section{Evaluation of antibacterial activity}

$\beta$-Sitosterol (compound 1) and its semisynthetic derivatives (compounds 2-5) were tested in-vitro for their antibacterial activity against standard strains of Staphylococcus aureus ATCC 29213 and Escherichia coli ATCC 25922 to represent Gram-positive and Gram-negative organisms, respectively, using micro broth dilution method according to the guidelines given by Clinical and Laboratory Standards Institute (CLSI, 2018)

\section{Preparation of bacterial cultures}

The turbidity of overnight cultures of each organism was adjusted to $0.5 \mathrm{McF}$ arland standards and diluted 1:20 with sterile normal saline before inoculation $\left(5 \times 10^{6} \mathrm{CFU} \mathrm{mL}^{-1}\right)$ and it was administrated to the test plate within 15 minutes.

\section{Antibacterial susceptibility test}

$\beta$-Sitosterol (5.488 $\pm 0.001 \mathrm{mg})$ was dissolved in $1000 \mu \mathrm{L}$ of ethanol and diluted with $4 \mathrm{~mL}$ of Mueller-Hinton Broth (MHB) to obtain a 1024 ppm solution. Then a serial twofold dilution with MHB was made up to $0.5 \mathrm{ppm}$ in sterilized test tubes. The same procedure was carried out for the four semi synthesized derivatives. 96-Well plates were labelled and each test sample $(190 \mu \mathrm{L})$ was added to appropriate wells followed by $10 \mu \mathrm{L}$ of the bacterial suspension. The plate was then incubated at $37^{\circ} \mathrm{C}$ for $18-24 \mathrm{~h}$ and turbidity formation was assessed visually. The lowest concentration at which no visual growth observed was taken as the Minimum Inhibition Concentration (MIC) value. Oxacillin and amoxicillin were tested as the positive controls against $S$. aureus and E. coli, respectively and ethanol was tested as the negative control. The test was carried out in triplicate.

\section{RESULTS AND DISCUSSION}

\section{Isolation of $\boldsymbol{\beta}$-sitosterol and synthesis of its derivatives}

$\beta$-Sitosterol is a secondary metabolite present in thousands of higher plants and has been isolated from various resources (Sayeed, 2016). In the present study, $\beta$-sitosterol was isolated from avocado fruit pulps. However, the extraction was very difficult as it contains a relatively large amount of water and hence the fruit pulp was freezedried first and then, the residue was used for the extraction with DCM. Further, the dry loading method was applied in column separation of $\beta$-sitosterol from the crude oil extract since the crude oil had an affinity towards the glass walls. Avocado is quite rich in $\beta$-sitosterol and therefore, compound 1 was isolated with a yield of $0.28 \%$. The compound isolated was compared with the authentic sample using co-TLC elution with three different solvent systems and further confirmed with the spectroscopic data analysis. The important structural functionalities responsible for the aforementioned bioactivities of $\beta$-sitosterol are C5-C6 olefin and C3 hydroxyl group in addition to the tetracyclic core structure. Synthesis of derivatives was mainly designed by modifying those functional groups. 

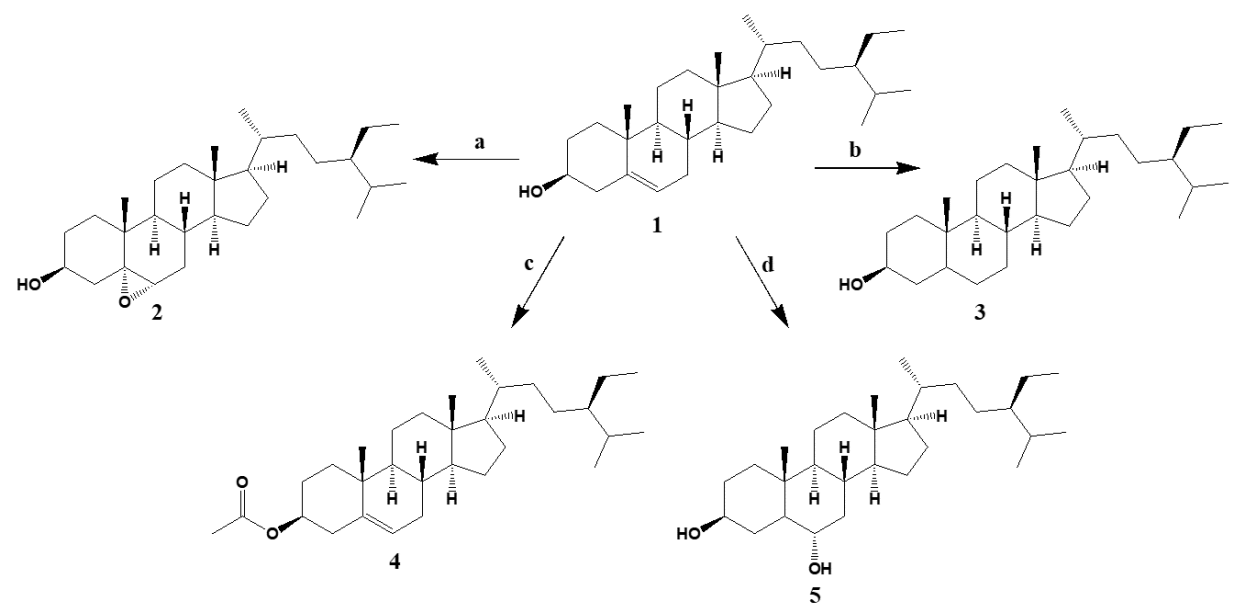

Reagents and conditions : (a)m-CPBA, DCM at ${ }^{\circ} \mathrm{C}$, (b)Pd/C, $\mathrm{H}_{2}, \mathrm{MeOH}$, rt. (c)Acetic anhydride, Pyridine, rt. (d)1)9-BBN, THF 2) $\mathrm{H}_{2} \mathrm{O}_{2}, \mathrm{NaOH}$

Figure 2: Semisynthetic derivatives of $\beta$-sitosterol, Compound 2-5.

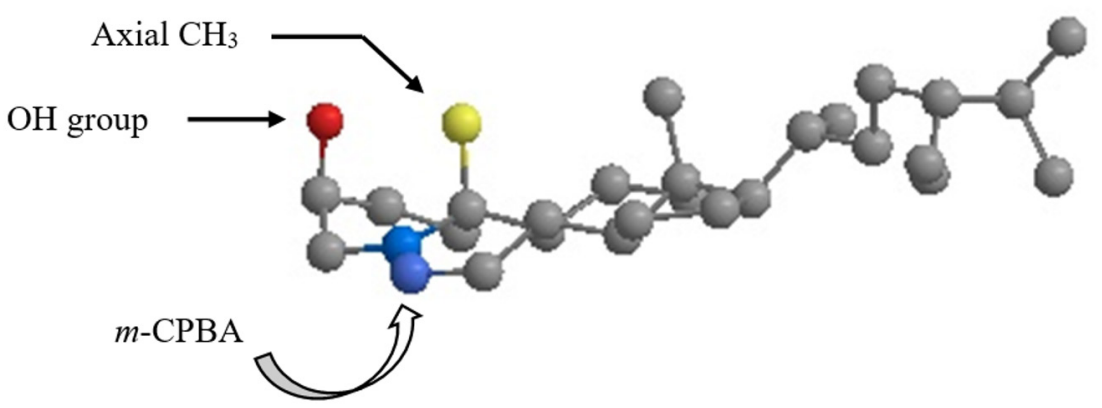

Figure 3: Attack of $m$-CPBA from the Si phase.

Figure 2 showed the schematic diagram with the reaction conditions used in the synthesis of semisynthetic derivatives of $\beta$-sitosterol (compounds 2-5). The 5-epoxy $\beta$-sitosterol (compound 2) was prepared by Prilezhaev reaction using $m$-CPBA and the product was obtained in 93\% yield. Even though two stereoisomers of epoxide ( $\alpha$ and $\beta$ ) were expected (Rega et al., 2007), the TLC pattern of the product mixture showed a single spot even in different solvent systems, which indicates the formation of one product. A similar study related to cholesterol, reported by Poirot and Silvente-Poirot explained that the $\alpha$ and $\beta$ epoxides of cholesterol could be easily identified based on the ${ }^{1} \mathrm{H}$ NMR spectral signals of H6. The $\alpha$ epoxide has a H6 proton signal around $2.75-2.95 \mathrm{ppm}$ while the $\beta$ epoxide has a H6 proton signal around $3.00-3.15 \mathrm{ppm}$. Since the H6 proton signal of compound 2 has a ppm value of 2.9, it evidenced the formation of the product, $\alpha$ epoxide of $\beta$-sitosterol (Poirot and Silvente-Poirot, 2013). Further, $\alpha$ epoxide formation would be the favoured product due to the steric hindrance caused by axial methyl group and hydrogens in adjacent carbons on the Re phase which facilitate the attack of $m$-CPBA from the Si phase (Figure 3) (Elgendy et al., 2007).

The disappearance of the $\mathrm{C} 6$ olefinic proton peak at $5.33 \mathrm{ppm}$ and the appearance of a new doublet at $2.91 \mathrm{ppm}$ in the resulting ${ }^{1} \mathrm{H}-\mathrm{NMR}$ spectrum confirmed the formation of the epoxide. In addition, the disappearance of the
$\mathrm{C}=\mathrm{C}$ bond stretching peak at $1654 \mathrm{~cm}^{-1}$ in the IR spectrum also supported the formation of the desired product.

$\beta$-Sitosterol was subjected to hydrogenation over $\mathrm{Pd} / \mathrm{C}$ in methanol at room temperature under a hydrogen atmosphere to yield compound 3 in $96 \%$ yield. Augustine and Reardon report that $\mathrm{Pd}$ is the best catalyst to perform hydrogenation of sterols due to its reactivity and ability to give the pure isomeric product (Augustine and Reardon, 1969). Spectral signals of this compound showed the absence of peaks that arise due to the C6 olefinic proton in ${ }^{1} \mathrm{H}-\mathrm{NMR}$ at $5.33 \mathrm{ppm}$ and $\mathrm{C}=\mathrm{C}$ stretching peaks at $1654 \mathrm{~cm}^{-1}$ in IR confirmed loss of unsaturation during the reaction.

The acyl ester of $\beta$-sitosterol (compound 4) was synthesized upon reaction with acetic anhydride in pyridine in a $96 \%$ yield. Distillation of pyridine over $\mathrm{KOH}$ resulted in a higher yield and shorter reaction time. The ${ }^{1} \mathrm{H}-\mathrm{NMR}$ spectrum of product 4 clearly showed the upper field shift of the C3 proton peak from 3.51 to $4.62 \mathrm{ppm}$ due to the substitution of an acyl group. In addition, the broad peak around $3400 \mathrm{~cm}^{-1}$, which is responsible for the $\mathrm{C} 3$ hydroxyl group was absent in the IR spectrum and a new peak at $1715 \mathrm{~cm}^{-1}$ due to the $\mathrm{C}=\mathrm{O}$ stretching of acyl ester was observed.

Anti-Markovnikov hydration was carried out to add a hydroxyl functional group (-OH) to the C6 position using 
Table 1: Minimum Inhibitory Concentration values of $\beta$-sitosterol and its derivatives.

\begin{tabular}{cccccccc}
\hline & \multicolumn{7}{c}{ MIC values of the compounds (ppm) } \\
\cline { 2 - 8 } Bacterial Strain & 1 & 2 & 3 & 4 & 5 & PC & NC \\
\hline S. aureus & 512 & 512 & $>1024$ & $>1024$ & 512 & $<1^{\mathrm{a}}$ & $>1024$ \\
$\boldsymbol{E}$. coli & 512 & 512 & $>1024$ & $>1024$ & 512 & $4^{\mathrm{b}}$ & $>1024$ \\
\hline
\end{tabular}

A - Oxacillin; b - Amoxicillin; PC - Positive Control; NC - Negative Control.

the two-step method, hydroboration followed by oxidation, and compound 5 has resulted in a $70 \%$ yield. In the present study, only the $6 \alpha$ product was obtained since only the Si face attack of 9-BBN is feasible due to the steric hindrance of the methyl group on Re face and the bulky nature of the 9-BBN. Bracher and Litz reported that the desired product could be achieved in high regio-selectivity in good yield with the use of 9-BBN due to its bulky nature (Bracher and Litz, 1996). The ${ }^{1} \mathrm{H}-\mathrm{NMR}$ spectrum showed the peak at $3.85 \mathrm{ppm}$ in addition to the $\mathrm{C} 3$ proton peak at $3.82 \mathrm{ppm}$ which indicates the presence of another carbinol proton at C6 where the new hydroxyl group was introduced. Additionally the absence of corresponding peaks for C6 olefinic proton in ${ }^{1} \mathrm{H}-\mathrm{NMR}$ between $4 \mathrm{ppm}$ and $6 \mathrm{ppm}$ and $\mathrm{C}=\mathrm{C}$ stretching peaks around $1450 \mathrm{~cm}^{-1}$ in IR spectra, also confirmed the formation of C6-hydroxyl.

Although derivatives of $\beta$-sitosterol such as longchain esters (Farshori et al., 2009) and epoxide (Zhang et al., 2005) have been synthesized, the addition of a hydroxyl group at $\mathrm{C} 6$ position through anti-Markovnikov hydration has not been reported to the best of our knowledge.

\section{In-vitro antibacterial activity}

$\beta$-Sitosterol and its semi-synthetic derivatives (compound 2-5) were subjected to in vitro antibacterial activity study against $S$. aureus ATCC 29213 and E. coli ATCC 25922 using micro broth dilution method according to the CLSI guidelines and results were summarized in Table 1. Antibacterial activity was measured in terms of minimum inhibition concentration (MIC) which is the lowest concentration of an antibiotic needed to inhibit the visible growth of a microorganism after overnight incubation.

In vitro antibacterial susceptibility, study results revealed that the starting material, $\beta$-sitosterol, and the semi synthesized products 2 and 5 obtained from epoxidation and anti-Markovnikov hydration, respectively have a MIC value of 512 ppm against both Gram-positive and Gramnegative organisms. However, MIC values of products 3 and 4 obtained from hydrogenation and acetylation were higher than 1024 ppm.

Different research groups reported that the MIC value of $\beta$-sitosterol is less than $100 \mathrm{ppm}$ against $S$. aureus (Sanches et al., 2005; Sen et al., 2012). In contrast, several research groups have reported a higher MIC value (1000 ppm) of $\beta$-sitosterol against $S$. aureus (Chandramu et al., 2003; Li et al., 2008; Kongkathip et al., 2009). However, our screening study showed that the MIC value for $\beta$-sitosterol using the micro broth dilution method is $512 \mathrm{ppm}$ for both organisms.

Based on our results, hydrogenation of the double bond at $\mathrm{C} 5-\mathrm{C} 6$ has decreased the antibacterial activity while the epoxidation and addition of a hydroxyl group at C6 was able to preserve its bioactivity. Acetylation at the $\mathrm{C} 3$ position has also reduced the antibacterial activity compared to the parent compound. Solubility of a drug substance is one of the parameters that decisively influence the therapeutic effects as it needs to be well balanced with sufficient hydrophilicity to be soluble in aqueous biological liquids and lipophilicity to penetrate through biological membranes (Mattson et al., 1977). Therefore decreased antibacterial activity of compounds 3 and 4 due to hydrogenation and acetylation may be due to the decrease of solubility as they reduce the polarity and increase the bulky nature compared to the parent compound in the biological system. Similar results have been reported by Silva et al. (2012) where they observed a reduction of antibacterial activity upon esterification of free hydroxyl at C3 in ursolic and oleanolic acids. However, incorporation of heteroatom to the ring system via epoxidation and hydroboration/ oxidation has no reduction of the activity though it removed the C5-C6 olefin. That could be since the parent molecule is highly lipophilic in nature and hence increase of hydrophilicity has no negative impact. These findings showed that hydroxyl functionally at $\mathrm{C} 3$ is essential for the activity; however $\mathrm{C} 3 \mathrm{OH}$ itself is not sufficient and hence it could be envisioned that the pharmacophore may consist of either full or partial tetracyclic ring with some kind of interaction through C5-C6 olefin, C5-C6 epoxide, and C6-hydroxyl.

\section{CONCLUSION}

$\beta$-Sitosterol has moderate antibacterial activity and was easily isolated from avocado fruit pulps with a $2.3 \%$ yield. Among the four derivatives synthesized via structural modifications of two functional groups, the compound with C6 hydroxyl of $\beta$-sitosterol was reported for the first time. According to the in-vitro antibacterial studies introduction of the epoxide ring system to the C5-C6 bond or a hydroxyl group at the $\mathrm{C} 6$ position has not decreased the bioactivity while removal of the C5-C6 double bond and protection of the $\mathrm{C} 3$ hydroxyl group has reduced the activity. Hence, it can be concluded that the presence of C5-C6 olefin, C5-C6 epoxide, and C6 hydroxyl along with the hydroxyl group at the $\mathrm{C} 3$ position has a great influence on its antibacterial activity. 


\section{ACKNOWLEDGEMENT}

We acknowledge the Department of Microbiology, Faculty of Medicine, University of Peradeniya, Peradeniya, Sri Lanka for providing standard bacterial strains for the study.

\section{DECLARATION OF CONFLICT OF INTEREST}

The authors declare that no conflicts of interest.

\section{REFERENCES}

Augustine, R.L. and Reardon Jr, E.J. (1969). The palladium catalyzed hydrogenation of cholesterol. Organic Preparations and Procedures 1(2): 107-109. DOI: https://doi.org/10.1080/00304946909458362.

Bracher, F. and Litz, T. (1996). 9-Borabicyclo [3.3. 1] nonane (9-BBN) in organic synthesis. Journal für Praktische Chemie/Chemiker-Zeitung 338(1): 386389. DOI: https://doi.org/10.1002/prac.19963380175.

Bygbjerg, I.C. (2012). Double burden of noncommunicable \& infectious diseases in developing countries. Science 337(6101): 1499-1501. DOI: https:// doi.org/10.1126/science.1223466.

Chandramu, C., Manohar, R.D., Krupadanam, D.G. and Dashavantha, R.V. (2003). Isolation, characterization $\&$ biological activity of betulinic acid \& ursolic acid from Vitex negundo L. Phytotherapy Research: An International Journal Devoted to Pharmacological and Toxicological Evaluation of Natural Product Derivatives 17(2): 129 - 134.

Clinical and Laboratory Standards Institute. Performance standards for antimicrobial susceptibility testing. $27^{\text {th }}$ ed. CLSI supplement M100. Wayne, PA: CLSI; 2018. ISBN-56238-804-5.

Coker, R.J., Hunter, B.M., Rudge, J.W., Liverani, M. and Hanvoravongchai, P. (2011). Emerging infectious diseases in southeast Asia: regional challenges to control. The Lancet 377(9765): 599 - 609. DOI: https:// doi.org/10.1016/S0140-6736(10)62004-1.

Elgendy, E.M. and Al-Ghamdy, H. (2007). Thermal and photooxidation reactions of the steroids: $\beta$-sitosterol, stigmasterol and diosgenin. Taiwan Pharm Journal 59: 113 - 2 .

Evidente, A., Venturi, V., Masi, M., Degrassi, G., Cimmino, A., Maddau, L. and Andolfi, A. (2011). In vitro antibacterial activity of sphaeropsidins \& chemical derivatives toward Xanthomonas oryzae pv. oryzae, the causal agent of rice bacterial blight. Journal of natural products 74 (12): 2520 - 2525. DOI: https://doi. org/10.1021/np200625m.

Farshori, N.N., Banday, M.R., Zahoor, Z. and Rauf, A. (2010). DCC/DMAP mediated esterification of hydroxy $\&$ non-hydroxy olefinic fatty acids with $\beta$-sitosterol: In vitro antimicrobial activity. Chinese Chemical Letters 21(6): 646 - 650. DOI: https://doi.org/10.1016/j. cclet.2010.01.003.

Food and Drug Administration. FDA labelling information. Available from: http://www.accessdata.fda.gov/drugs atfda_docs/label/2009/022110s000lbl.pdf (March $9^{\text {th }}$ 2021).
Ge, M., Chen, Z., Russell, H., Kohler, J., Silver, L.L., Kerns, R., Fukuwaza, S., Thompson, C. and Kahne, D. (1999). Vancomycin derivatives that inhibit peptidoglycan biosynthesis without binding D-Ala-DAla. Science 284(5413): 507-511. DOI: https://doi.org/ 10.1126/science.284.5413.507.

Kongkathip, N., Sam-ang, P., Kongkathip, B., Pankaew, Y., Tanasombat, M. and Udomkusonsri, P. (2009). Development of patchouli extraction with quality control and isolation of active compounds with antibacterial activity. Agriculture and Natural Resources, 43(3), 519525. Available from: https://li01.tci- thaijo.org/index. php/anres/article/view/244698/167189 (December $6^{\text {th }}$ 2017).

Lalitha, M.K. (2004). Manual on antimicrobial susceptibility testing. Performance Standards for Antimicrobial Testing: Twelfth Informational Supplement 56238: 454-456. Available from:https:// www.biodiamed.gr/wpcontent/uploads/2017/06/ Manual_on_Antimicrobial_Susceptibility_Testing.pdf (December $\overline{6}^{\text {th }}$ 2017).

Li, W.H., Chang, S.T., Chang, S.C. and Chang, H.T. (2008). Isolation of antibacterial diterpenoids from Cryptomeria japonica bark. Natural Product Research 22(12): 1085 $-1093$.

Mattson, F.H., Volpenhein, R.A. and Erickson, B.A. (1977). Effect of plant sterol esters on the absorption of dietary cholesterol. The Journal of Nutrition 107(7): 11391146. DOI: https://doi.org/10.1093/jn/107.7.1139.

Nagarajan, R. (1993). Structure-activity relationships of vancomycin-type glycopeptide antibiotics. The Journal of antibiotics 46(8): 1181-1195. DOI: https://doi.org/ 10.7164/antibiotics.46.1181.

Newmann, D.J. and Gordon, M.C. (2016). Natural products as sources of new drugs from 1981 to 2014. Journal of Natural Products 79: 629-666. DOI: https://doi. org/10.1021/acs.jnatprod.5b01055.

Parvin, S., Kader, M.A., Muhit, M.A., Haque, M.E., Mosaddik, M.A. and Wahed, M.I.I.(2011). Triterpenoids and phytosteroids from stem bark of Crataeva nurvala buch ham. Journal of Applied Pharmaceutical Science 1(9): 47-50.

Poirot, M. and Silvente-Poirot, S. (2013). Cholesterol-5, 6-epoxides: chemistry, biochemistry, metabolic fate and cancer. Biochimie 95(3): 622-631. DOI: https://doi. org/10.1016/j.biochi.2012.05.006.

Rali, S., Oyedeji, O.O., Aremu, O.O., Oyedeji, A.O. and Nkeh-Chungag, B.N. (2016). Semisynthesis of derivatives of oleanolic acid from Syzygium aromaticum \& their antinociceptive \& anti-inflammatory properties. Mediators of Inflammation 2016: 1-9. DOI: http://dx.doi.org/10.1155/2016/8401843.

Rega, M., Jiménez, C. and Rodríguez, J. (2007). 6E-Hydroximinosteroid homodimerization by crossmetathesis processes. Steroids 72(11): 729 - 735. DOI: https://doi.org/10.1016/j.steroids.2007.03.014.

Saeidnia, S., Manayi, A., Gohari, A.R. and Abdollahi, M. (2014). The story of beta-sitosterol; European Journal of Medicinal Plants 4: 590-609. DOI: https://doi.org/ 10.9734/EJMP/2014/7764. 
Sanches, N.R., Garcia Cortez, D.A., Schiavini, M.S., Nakamura, C.V. and Dias Filho, B.P. (2005). An evaluation of antibacterial activities of Psidium guajava (L.). Brazilian Archives of Biology and Technology 48(3): 429-436. DOI: http://dx.doi.org/ 10.1590/S1516-89132005000300014.

Sasidharan, S., Chen, Y., Saravanan, D., Sundram, K.M. and Latha, L.Y. (2011). Extraction, isolation $\&$ characterization of bioactive compounds from plants' extracts. African Journal of Traditional, Complementary and Alternative Medicines 8(1): 1 - 10. DOI: https://doi.org/10.4314/ajtcam.v8i1.60483.

Sayeed, B., Shahdaat, M., Karim, S.M.R., Sharmin, T. and Morshed, M.M. (2016). Critical analysis on characterization, systemic effect, \& therapeutic potential of beta-sitosterol: a plant-derived orphan phytosterol. Medicines 3(4): 29. DOI: https://doi. org/10.3390/medicines3040029.
Sen, A., Dhavan, P., Shukla, K.K., Singh, S. and Tejovathi, G. (2012). Analysis of IR, NMR \& antimicrobial activity of $\beta$-sitosterol isolated from Momordica charantia.

Silva, M.L., David, J.P., Silva, L.C.R.C., Santos, R.A.F., David, J.M., Lima, L.S., Reis, P.S. and Fontana, R. (2012). Bioactive oleanane, lupane \& ursane triterpene acid derivatives. Molecules 17: 12197 - 12205. DOI: https://doi.org/10.3390/molecules171012197.

Wang, W., Zhao, Y., Rayburn, E.R., Hill, D.L., Wang, H. and Zhang, R. (2007). In vitro anti-cancer activity and structure-activity relationships of natural products isolated from fruits of Panax ginseng. Cancer Chemotherapy and Pharmacology 59(5): 589-601. DOI: https://doi.org/10.1007/s00280-006-0300-z.

World Health Organization. (1999). The world health report: 1999: making a difference. World Health Organization. 1 - 36. Available from: https://apps.who. int/iris/handle/10665/42167 (December 10 $0^{\text {th }} 2017$ ). 